\title{
1. Not a straightforward path: developing and evaluating infrastructure projects
}

\subsection{THE COMPLEXITY OF DEVELOPING INFRASTRUCTURE PROJECTS}

Evaluations of complex infrastructure projects require methods that do justice to this complexity. Studies of single cases can adequately deal with this complexity, but have difficulty in identifying the generic patterns across cases. Conversely, large-n studies can adequately identify recurring patterns, but do not perform quite as well when it comes to reflecting the complexity of the case. In this book, we present, explain, and demonstrate Qualitative Comparative Analysis (from here on abbreviated as QCA) as a valuable evaluation method that strikes a balance between the qualities of the single-n case study and the qualities of the large-n study. But before we dive into the method, let us first have a brief look at what the complexity of infrastructure projects actually entails. The A15 Maasvlakte-Vaanplein mega-project provides a telling example.

The port of Rotterdam, located in the delta of the rivers Rhine and Meuse, is the largest European port by many measures (Port of Rotterdam, 2015). The port's recent extension of 2000 hectares, the so-called Second Maasvlakte, led the Dutch government to undertake a major upgrade and reconstruction of the $37 \mathrm{~km}$ long A15 highway corridor that connects the Maasvlakte port area with the European hinterland (Minister van Verkeer and Waterstaat, 2010; Ministerie van Infrastructuur en Milieu, 2014; see Figure 1.1). The massive operation was deemed necessary to increase traffic flow and safety on the corridor. Many of the actors involved thought that the project should be carried out as soon as possible, but it was also clear that the investments would stretch the government's budget. Considering this, the government decided to tender the project. Rijkswaterstaat, the executive agency of the Ministry of Infrastructure and Water Management, was made responsible for the tendering. The tender was awarded to a construction consortium called A-Lanes A15. This consortium consisted of four large international construction companies: 


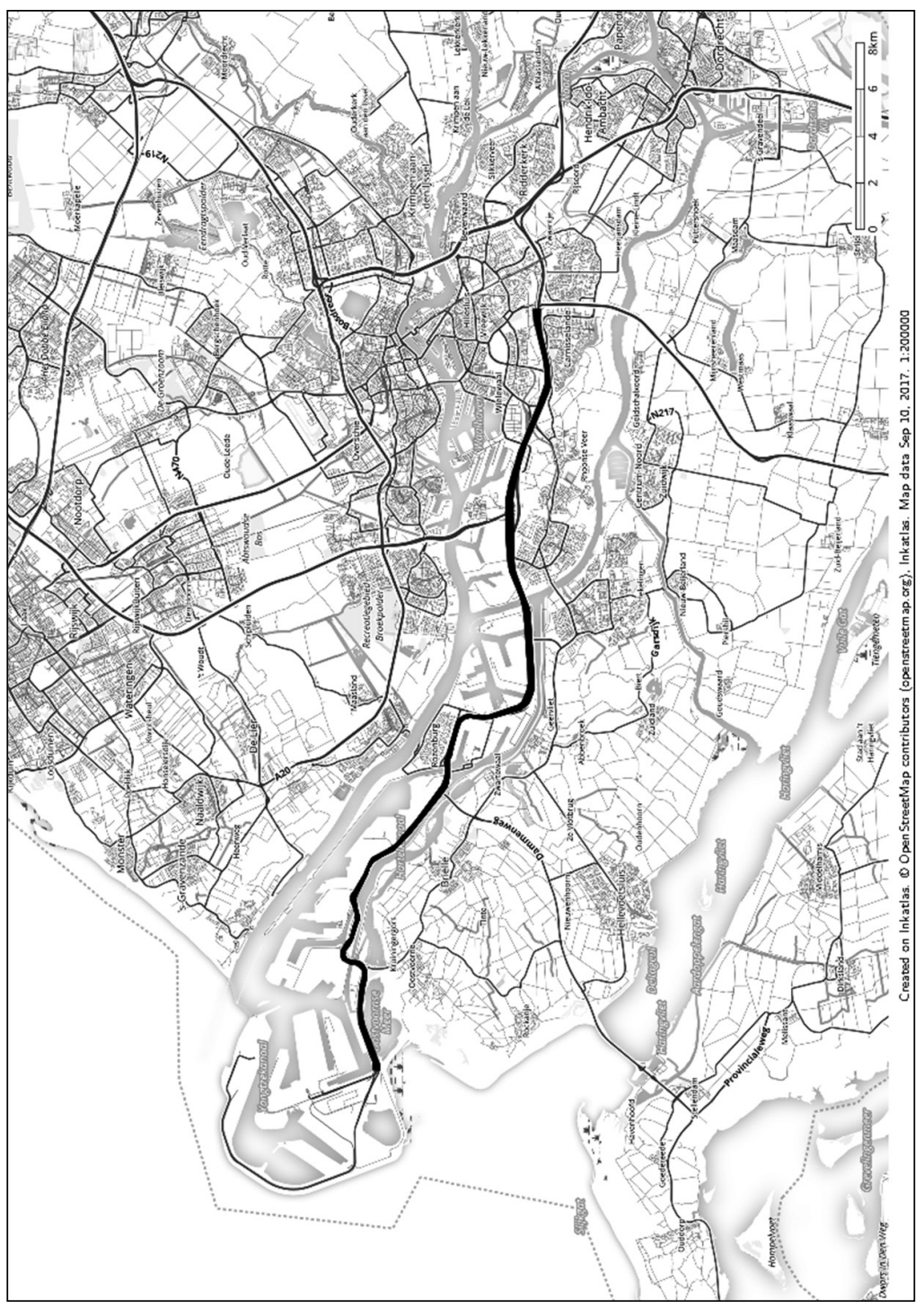

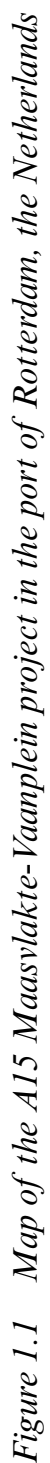


Ballast Nedam, John Laing, Strabag, and Strukton. The project's scope, aims, and budget were enormous. It included the design, build, and maintenance (until the year 2035) of $85 \mathrm{~km}$ of additional traffic lanes, the development and implementation of a dynamic traffic management system, the renovation of 36 civil structures and the construction of 12 new ones, the renovation of two large tunnels, and the construction of the new Botlekbridge - one of the largest and heaviest vertical lift bridges in the world, and the largest one in Europe (A-Lanes A15, 2013). Totaling a value of over $€ 2$ billion (Ministerie van Infrastructuur en Milieu, 2014), the A15 Maasvlakte-Vaanplein was the largest project ever tendered by Rijkswaterstaat (A-Lanes A15, 2010; Eversdijk et al., 2011).

Not only was the A15 Maasvlakte-Vaanplein a massive project in terms of budget and scope, it was also one of the first Design-Build-FinanceMaintain (DBFM) projects tendered by Rijkswaterstaat (Eversdijk et al., 2011; Neerlands Diep, 2016). DBFM is a far-reaching type of PublicPrivate Partnership (PPP) where the private partner is wholly responsible for designing, building, financing, and maintaining the infrastructure for a given period of time (Lenferink et al., 2013). This type of PPP contract was largely untested in the Netherlands (cf. Klijn, 2009). It required a change in the distribution of roles, tasks, and responsibilities between public and private actors, compared to what the actors were historically accustomed to (Gras, 2011). Rijkswaterstaat, by origin and in tradition itself a public engineering organization that is now a governmental agency (Metze, 2010; Van den Brink, 2009), had to operate at more distance from the market parties so as to incentivize the market to maximally deploy its design, build, finance, and maintenance capabilities. In this new situation, it is the private partner that has become responsible for the tasks that were historically done by Rijkswaterstaat. Because of its sheer size and its new and innovative nature, in the Netherlands the A15 Maasvlakte-Vaanplein project was leading by example. It was hoped that this type of contracting would present new ways in which infrastructure in the Netherlands could be developed and maintained more efficiently, more effectively, and resulting in increased levels of quality in projects. Being the proverbial prototype with respect to both size and contract, this significantly added to the project's complexity.

The complexity of the project was further increased by the fact that it runs straight through one of the main economic and industrial zones of the Netherlands: a densely built industrial, trading, and residential area that is packed with infrastructure, both above the ground as well as below the ground in the shape of subterranean cables and pipelines (Verkeerskunde, 2012). Many of these conditions were known, for example, through Geographic Information Systems and historical records. But 
there were also unknown conditions: for example, the area was heavily bombed during World War II, so there was a real possibility that unexploded bombs could be found when digging into the ground. Some of the soil conditions could only be determined during the construction phase. And there was no way of telling exactly how the social environment, i.e., the people living and working in the vicinity of the project, would respond to the project (Verweij, 2015a).

The known and unknown conditions required careful maneuvering when designing and constructing the highway project - not an easy task when the pressure is on. Adding to the complexity of the environment described above was a complex institutional setting that, in many ways, presented as much uncertainty as did the old explosives hidden in the soil. Not only had the relationships with a variety of (semi-)public stakeholders to be managed, such as the relationships with the Port of Rotterdam Authority and various municipalities (Verweij, 2015a; Verweij et al., 2014), the project also had to deal with many internal stakeholders such as financiers, contractors, subcontractors, and shareholders (cf. De Schepper et al., 2014). Given the complexity of the project in terms of scope and construction, its environment, as well as its institutional setting, it is justified to say that the A15 Maasvlakte-Vaanplein was a complex project: many known and unknown conditions could influence, and did influence, the project's development (Verweij, 2015b; see Figure 1.2).

Because of their complexity, the trajectories of infrastructure projects often unfold differently from what was hoped and planned (Teisman et al., 2009a; Teisman et al., 2009b; Verweij, 2015b). The A15 MaasvlakteVaanplein project was no exception. In 2014, the Dutch newspaper Het Financieele Dagblad published an article titled 'Contractors struggle with A15 Maasvlakte-Vaanplein', reporting a cost overrun of $€ 217$ million and counting. The article described that the problems were due to ever-changing demands from the principal Rijkswaterstaat, and due to the huge amount of permits required and stakeholder interests involved. A case study into the project also pointed to an initial misfit between management strategies and the societal dynamics caused by stakeholders on the one hand, and the inflexible nature of the DBFM contract on the other hand, as explanations for the problems (Reynaers and Verweij, 2014; Verweij, 2015a). Later that year, the same newspaper reported that the cost overrun had further increased to $€ 253$ million, resulting in growing tensions between the public and private parties. Worse, still, was that the end of those increasing costs was not yet in sight (Verbraeken and Weissink, 2014). The project had turned from a prestigious and innovative PPP contract into a problematic endeavor with significant time and budget overruns. Naturally, a fight ignited between Rijkswaterstaat 


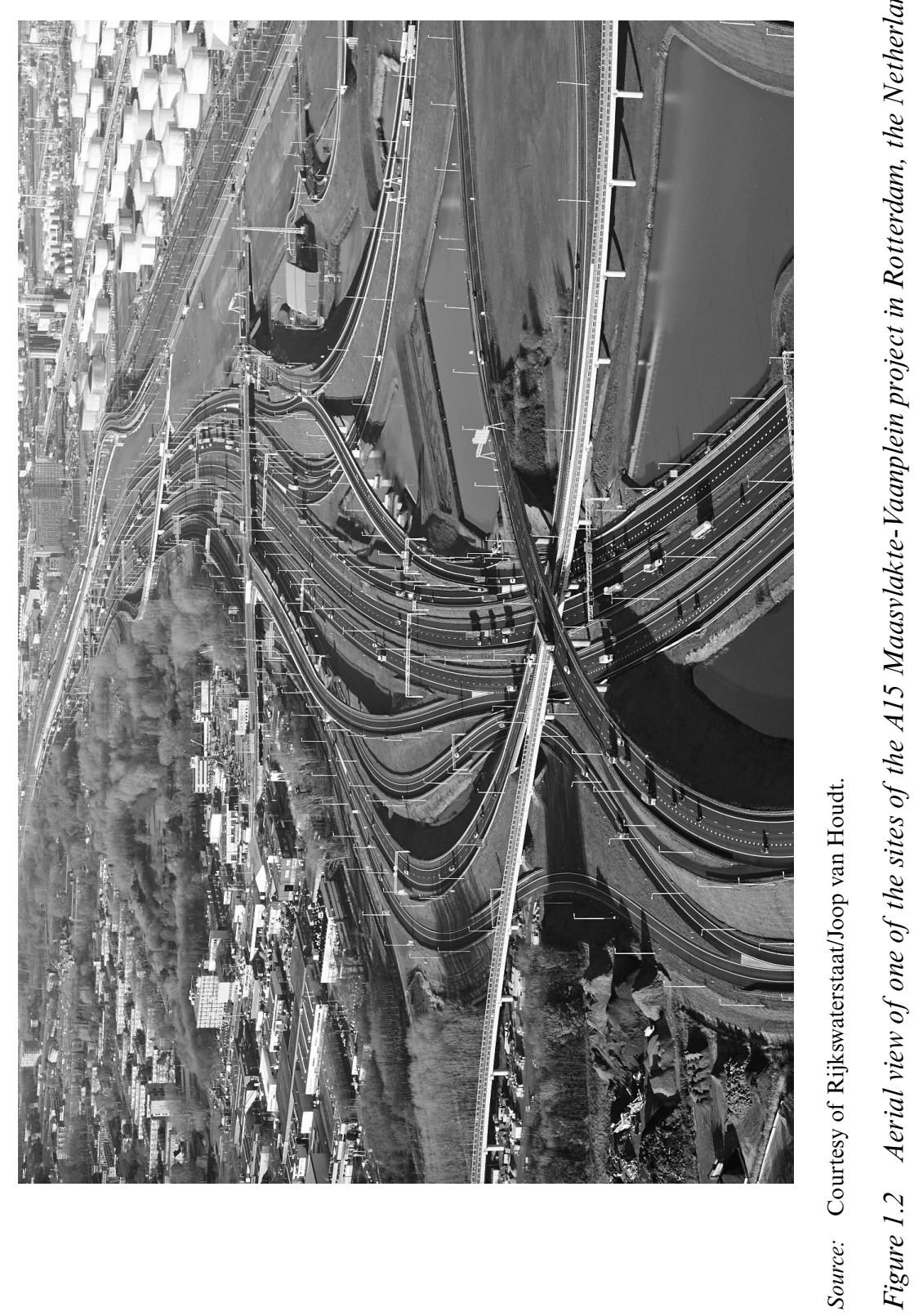


and its private partner, A-Lanes A15, about who was responsible for the project's problems (Houtekamer, 2015).

By no means is the A15 Maasvlakte-Vaanplein project exceptional in its complexity. Infrastructure projects often unfold differently to what was planned and hoped (Sanderson, 2012; Teisman et al., 2009b), frequently resulting in, for example, missed deadlines and budget overruns (Cantarelli, 2011; Flyvbjerg, 2014; Flyvbjerg et al., 2003a; Merrow, 1988) or other types of (undesirable) outcomes (see e.g., Dimitriou et al., 2013; cf. Atkinson, 1999). Given the fact that so many of these projects appear to succumb to seemingly similar problems, it is pivotal that they are evaluated systematically so that future projects can be done better and tax money can be saved (Short and Kopp, 2005).

This, then, is our argument in a nutshell: the systematic evaluation of such projects must acknowledge the complexity of the projects explicitly, in order not to fall into the trap of producing unrealistically simplified accounts of projects that do not adequately reflect the real challenges involved in their development. Unfortunately, too often evaluations fall into that trap and do not seem to produce anything useful beyond the tired clichés that projects are complex and difficult to manage. Evaluations that are serious about incorporating the complexity of projects need to address three principal aspects of infrastructure projects' complexity: heterogeneity, uniqueness, and context (cf. Verweij, 2015b; 2017; Verweij and Gerrits, 2013).

1. First, heterogeneity points to the fact that the development of infrastructure projects involves many actors, and that these actors have, amongst other things, different (and often conflicting) perspectives, values, interests, and hence goals (Lehtonen, 2014). This actor-heterogeneity is a major, but under-appreciated, aspect of the complexity of projects (Bosch-Rekveldt, 2011; Zeng et al., 2015). Projects are embedded in networks of both internal and external heterogeneous actors, who have stakes in the project and who like to see their stakes served or protected (De Schepper et al., 2014). If they feel their stakes are insufficiently protected, the actors may try to influence the project by deploying resources, ranging from generating media exposure to starting legal procedures, to exerting various other forms of (obstruction) power (Klijn and Koppenjan, 2016; Koppenjan and Klijn, 2004).

2. The second aspect concerns the uniqueness of projects. Each project is, to some extent, unique (Vidal and Marle, 2008). Existing project-specific configurations of cables, pipelines, and other physical (both natural and manmade) structures, together with existing configurations of social and institutional structures (including laws and regulations), largely 
determine (or more negatively: restrict) what is possible in terms of designing and planning a project (Marshall, 2009; Verweij and Gerrits, 2013; Verweij et al., 2014). The unique configuration of physical and social aspects (see e.g., Bijker, 1997) in a project also gives rise to events during the development of the project that are specific to the project. Because of the uniqueness of projects, there is often a 'lack of previous experience of sufficiently similar projects' (Lehtonen, 2014, p. 280).

3. The third aspect is context. Projects are open systems, or, to put it in more practical terms: 'no project is an island' (Engwall, 2003). Infrastructure projects interact with their socio-physical environment, and the projects might change with their contexts because the contexts are dynamic and change in often unpredictable ways (Dimitriou, 2014; Dimitriou et al., 2013; Teisman et al., 2009b; Verweij, 2015b). For instance, ground or weather conditions may alter and stakeholder preferences can shift. Infrastructure project developers can try to cope with such contextual influences (Beitsch and Lawther, 2015; Charoenngam and Yeh, 1999; Miller and Lessard, 2000; Thomas and Mengel, 2008), but they will not be able to fully shield a project from being influenced. Context has a massive impact on the development of projects (Vidal and Marle, 2008; see Figure 1.3).

Our argument is that infrastructure projects are complex and the methods to analyze them need to be well suited to take this complexity into account. This is, of course, not exactly a novel insight (see e.g., Baccarini, 1996; Bertelsen, 2003; Teisman et al., 2009a). However, there is a problem with how explanations about the outcomes - or effects, performance, or results - of infrastructure projects are generated in evaluations (Smyth and Morris, 2007; Verweij and Gerrits, 2013). Often, evaluations rely on single case studies (e.g., Neerlands Diep, 2016; Nijland et al., 2010). These are useful because they can generate (an) explanation(s) of a particular case, simply because single cases allow the researcher to focus on the heterogeneous, unique, and contextual nature of a project. However, by implication, the relevance of a case study for explaining other (future) projects is rather limited (Smyth and Morris, 2007). In contrast, larger-n studies allow the comparison of cases (e.g., Flyvbjerg et al., 2003a), but, by implication, their relevance for explaining single projects is limited as they cannot incorporate heterogeneity, uniqueness, and context in the mode of explanation very well (Smyth and Morris, 2007). In addition, such studies are geared towards finding that single variable that controls for the project's outcome. Naturally, this violates the aspect of uniqueness. As such, we find ourselves at a conundrum. 


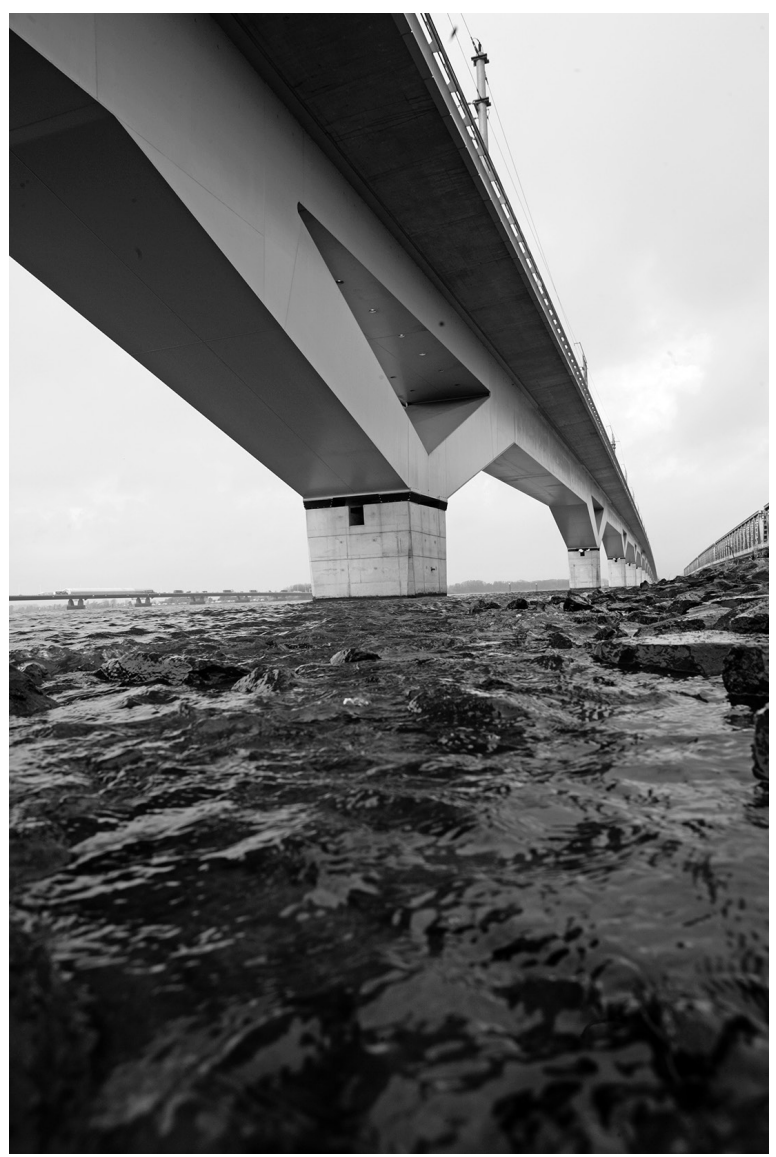

Source: Courtesy of Rijkswaterstaat.

Figure 1.3 The new railway bridge at Moerdijk, the Netherlands, is part of the HSL-Zuid megaproject. We will discuss this project in Chapter 2

\subsection{ILLUSTRATING THE CONUNDRUM}

Flyvbjerg and colleagues conducted a famous study into the cost performance of large infrastructure projects worldwide (Flyvbjerg et al., 2003a; Flyvbjerg, et al. 2002; 2003b; 2004; 2005). They compared 258 projects in 20 different countries and found a number of patterns. For instance, cost overruns were a global phenomenon, the actual costs of projects were on 
average 45 percent higher than the estimates, and cost performance had not improved in the 70 years up to their study. Their findings are of indisputable importance, inter alia in addressing the problem of the continuous underperformance of infrastructure project development. However, the study lacks in explanatory value, i.e., in explaining the deeper causes of the lackluster performance of such projects (Verweij and Gerrits, 2013). Flyvbjerg and colleagues propose the strategic rent-seeking behavior of actors as the explanation for the cost overruns (Flyvbjerg, 2009a; 2009b; Flyvbjerg et al., 2003a; Flyvbjerg et al., 2002). That is, that 'project underperformance is a function of pre-planned opportunistic behavior by key vested interests leading to the regular approval of non-viable projects' (Sanderson, 2012, p. 440). However, by its very nature, their large-n study cannot explain the influence of the unique and contextual conditions on the cost underperformance of individual projects (Verweij and Gerrits, 2013). In other words, while there is merit in their explanation, there is no way of telling how underperformance is achieved in any single project within the dataset.

Here, we arrive at the core matter of the argument. While Flyvbjerg et al.'s (2003a) study points to many similarities amongst projects at the population level of the sample, there may very well be (very) different ways in which this similarity is produced in individual projects. In more formalistic terms: the causal combinations of conditions producing seemingly similar results are different - note the plural in 'combinations' here. For instance, the Øresund Link and Channel Tunnel were reasonably similar regarding the scope, the size, and the percentage of cost overrun (Flyvbjerg et al., 2003a; cf. Ward et al., 2014). However, a case study by Anguera (2006) into the Channel Tunnel's cost performance revealed that there were quite a few varied conditions that impacted the performance of the project, including: the absence of a clear project owner from the outset of the project, the unforeseen advent of low-cost airlines leading to reduced train ridership, political events involving the British and French governments, difficult ground conditions, and even more or less random events such as the Pan Am crash at Lockerbie. Although the Øresund Link project may be similar in some of these aspects, this specific set of explanatory conditions (from absence of ownership to the Lockerbie disaster) does not account for its cost overruns. Flyvbjerg et al. (2003a, p. 19) themselves also recognized this: 'for the Channel Tunnel, changed safety requirements were a main cause of overrun ... For the Øresund Link, it proved more costly than estimated to carve major new transport infrastructure into densely populated Copenhagen . . .'

We want to stress that we consider the study by Flyvbjerg and his colleagues highly useful. The purpose of our example here is to illustrate the conundrum in infrastructure evaluation. On the one hand, single-n case studies, such as Anguera's (2006) evaluation of the Channel Tunnel or an 
evaluation of the A15 Maasvlakte-Vaanplein project (Neerlands Diep, 2016), generate rich data and give important insights into the heterogeneous, unique, and contextual nature of individual projects. However, such case study evaluations do not contribute much to the identification of generic patterns that determine the outcomes of multiple infrastructure projects. On the other hand, large-n studies, such as the one by Flyvbjerg et al. (2003a) discussed above, provide important insights into the generic patterns, but do not allow a detailed analysis of the specific nature of the individual projects. The aim of this book, then, is to present an evaluation method that strikes a balance between the qualities of the single-n case study and large-n studies.

\subsection{A SOLUTION TO THE CONUNDRUM: QUALITATIVE COMPARATIVE ANALYSIS}

We find a solution to the conundrum in the use of QCA (Ragin, 1987; 2000; 2008b) for the evaluation of infrastructure projects. QCA reconciles the focus on rich details from individual in-depth studies with the focus on the identification of causal patterns across cases. The importance of reconciling both foci is recognized in infrastructure research (see e.g., Dainty, 2008; Fellows and Liu, 2015), but is yet little heeded (Verweij and Gerrits, 2013). Whereas current arguments concentrate on reconciling both foci through methodological pluralism - which might be critiqued because different methods carry with them different 'epistemological commitments' (Dainty, 2008, p. 9) that are incompatible - QCA offers a more epistemologically coherent and consistent solution to reconciling both foci (Gerrits and Verweij, 2013; Verweij and Gerrits, 2013).

QCA will help to remedy the gap between rich details and generic patterns in infrastructure project evaluation. Here, we understand evaluation as any attempt to research the causes that lead to the outcomes of infrastructure projects. We approach such projects or cases in general as complex systems. QCA is very well suited to research complexity (Byrne, 2002; 2005; 2009b; 2011a; 2011b; Gerrits, 2012; Gerrits and Verweij, 2013; 2016, Verweij, 2015b; 2017; Verweij and Gerrits, 2012; 2013).

The main power of QCA is that it allows evaluators (and researchers in general) to derive generic patterns from the intricate details of projects by systematically comparing any medium number of cases, while retaining an acceptable level of complexity in the patterns. QCA hinges on the notion of complex causality (Byrne, 2005; Byrne and Callaghan, 2014; Gerrits, 2012): it assumes a priori that outcomes in and of cases are generated - or 'produced' in its jargon - by combinations of conditions that together form 
configurations. In addition, it assumes that different configurations can produce a similar outcome, and that the effect of a condition depends on its combination with other conditions. In other words, QCA is highly sensitive to the complexity of conditions, whereas many other methods attempt to remove as much of this complexity as possible. This often leads to misguided attempts to find the one variable that determines the outcome, regardless of context. QCA offers the possibility to include the context in the research. As we have seen in the examples above, given the complexity of infrastructure projects, this inclusion is more than welcome. By comparing multiple detailed cases, similarities between cases with respect to their complex relationships can be identified, pointing to more generic patterns. At the same time, because various different configurations are allowed to be identified, the method facilitates highlighting the unique aspects of the cases. Using QCA in infrastructure evaluation research ultimately leads to the identification of (combinations of) necessary and/or sufficient conditions that explain the outcome of interest (Verweij, 2015b). This will contribute to learning for future projects.

In this book, we will explain the background of QCA and present concrete and easy-to-follow steps and procedures that allow readers to use the method in their own research. At this point, it is useful to mention that there is some jargon involved and that we will touch upon some very basic algebraic procedures. However, extensive knowledge of algebra is not required to continue reading this book or for using this method. We aim to provide an accessible introduction to QCA. We will explain everything in accessible language and provide ample examples to illustrate the details of the method. In doing so, we will build on the existing QCA literature, most importantly the seminal works by Ragin $(1987 ; 2000 ; 2008 b)$, textbooks on QCA (Rihoux and Ragin, 2009a; Schneider and Wagemann, 2012), and articles about QCA, including both methodological and empirical work (see www.compasss.org for an overview). Naturally, we will present our own particular approach to the method, focusing on infrastructure research. QCA is undergoing rapid methodological developments, mainly in the fields of Sociology and Political Science. We will borrow from these fields whenever necessary but, ultimately, we are interested in one practical question: can we get a better understanding of the complexity of infrastructure projects?

\subsection{WHY DID WE WRITE THIS BOOK (AND WHY SHOULD YOU READ IT)?}

This book has its origin in our practical observations that applied studies and evaluations of infrastructure projects often rely on comparative 
methods and techniques that are largely ignorant to incorporating the real complexity of the projects (Verweij and Gerrits, 2011; 2012; 2013). We also recognized the potential of QCA for solving the conundrum (Verweij and Gerrits, 2012; 2013). While the method was rapidly gaining traction in the social sciences (Rihoux et al., 2013), which is where we come from, infrastructure project researchers seemed yet largely unaware of its existence. There are very few QCA applications in the field. A few years ago, Jordan et al. (2011) identified only three such applications in the fields of Infrastructure, Transportation, and Construction project research (i.e., Bakker et al., 2011; Boudet et al., 2011; Gross and Garvin, 2011). QCA also seemed rather unknown outside of the academic world, even though evaluators and other practitioners did recognize the need for such a method. In the Netherlands, for instance, the Institute for Transport Policy Analysis strongly advocated more and improved infrastructure development evaluation to better understand why projects perform the way they do (Kennisinstituut voor Mobiliteitsbeleid, 2009). At the same time, this institute observed that evaluations suffered from methodological deficiencies (Kennisinstituut voor Mobiliteitsbeleid, 2009; Nijland et al., 2010) related to the misfit between the complexity of infrastructure projects and the methods used to evaluate them. Evaluations continued to cling to either (single) case study approaches or larger-n statistical approaches, thus maintaining the problem. Moreover, when multiple indepth case studies are conducted, it often proves difficult to compare them systematically and transparently (Aus, 2007).

It is against this background that we developed this book. We draw from a number of our own resources as well as the abovementioned seminal works, textbooks, and methodological articles. First and foremost, we have conducted multiple evaluations of infrastructure and spatial planning projects using QCA ourselves (Busscher et al., 2017; Kort et al., 2016; Li et al., 2016; Verweij, 2015a; 2015b; 2015c; Verweij and Gerrits, 2014; 2015; Verweij et al., 2013; Verweij et al., 2017), which made us appreciate the ways in which the method works. Secondly, we have taught courses on QCA to various audiences, ranging from Ph.D. and Master Students in academia, to evaluators in practice. These include courses at Erasmus University Rotterdam, the University of Bamberg, and the University of Groningen, but also presentations at the US General Accountability Office and at evaluation network meetings in the Netherlands and Flanders, and workshops in Germany and Switzerland. Thirdly, we have had many discussions - during conferences or simply at the coffee machine - with academics and practitioners, all of which helped us in focusing and developing our ideas.

Who should read this book? We want to cater to researchers and 
practitioners, such as evaluators working in private or public organizations who are involved in infrastructure and construction projects. We also believe that this book bears relevance for researchers and students in Engineering, Construction, and Infrastructure, and in the strongly related field of Project Management, who would like to do comparative research on infrastructure projects. In addition, the book can be used by students and researchers in the social sciences at large, who would like to learn about how QCA can be used to systematically uncover the complexity of the cases they study. As mentioned above, we will not partake in the very technical, methodological QCA debate that is currently taking place. Our primary mission is to present the basics of the method in an accessible way, so that any researcher sitting with a pile of data can get started in a few hours. Those readers that would like to know more about the methodological details and the rapid developments that are taking place within QCA are referred to www.compasss.org and to the bibliography of this book. And with that out of the way, we will now present an overview of the book.

\subsection{OVERVIEW OF THE BOOK}

This book is structured in five chapters. Highlights of each chapter are presented at the beginning of the chapters. The book follows the basic logic and steps of the full research process using QCA. This means that we will take the reader from a qualitative in-depth and contextualized understanding of multiple individual cases - via the reconstruction of these cases into quantified configurations of conditions and outcomes, and then the organization of these cases in a data matrix and subsequent so-called truth table - all the way up to the identification of generic patterns that recur across cases (see Rihoux and Lobe, 2009; Verweij, 2015b; 2017). The glossary by Thiem and Baumgartner is a useful compendium to this book. ${ }^{1}$

Chapter 2 focuses on the notion of the case in QCA in general, and in infrastructure development in particular. First and foremost, QCA is a qualitative and case-based method (Pattyn et al., 2015; Ragin, 1987). This means that the researcher needs to develop a thorough understanding of the cases that will be compared. QCA is also used in large-n research designs (see Rihoux et al., 2013). This use of the method, however, is difficult to reconcile with the need to research the heterogeneous, unique, and contextual nature of the projects. The chapter discusses why studying individual cases matters, how we conceive cases in QCA conceptually as complex configurations of conditions and an outcome, and how they can be studied in terms of data collection and analysis. 
Chapter 3 discusses how the rich qualitative data obtained from the individual cases have to be prepared for comparison. This means that those data will have to be quantified and transformed into a data matrix. This involves calibration. Through calibration, case data are systematically and transparently interpreted by first developing quantitative scales for each of the conditions and the outcome against which, secondly, cases are subsequently scored. The calibrated cases are then put in the calibrated data matrix, which lists the cases in the rows and the conditions and outcomes in the columns.

Chapter 4 focuses on the comparative procedures in QCA. This first involves the transformation of the data matrix into a truth table. In the truth table, similar cases are assigned to their corresponding combination of conditions represented by a truth table row, at the same time separating different cases from each other. The truth table is the key tool for the systematic comparison of the cases. The cases in the truth table are systematically compared in order to identify the recurring patterns and to separate those from the unique aspects of the cases. In practice, it means the pairwise comparison of truth table rows that agree on the outcome and differ in but one of the conditions. The primary output of the case comparison is a solution formula comprising of alternative, necessary and/ or sufficient conditions that explain the outcome for the cases involved in the analysis. Examples provided in the chapter will illustrate the iterative nature of the comparative process, where the researcher is involved in a 'dialogue between ideas (theory) and evidence (data)' (Ragin, 1987; Rihoux and Lobe, 2009).

We use Chapter 5, then, to reflect on the QCA method for the evaluation of infrastructure projects. We will discuss QCA's capacity to truly capture and study the complexity of the development of infrastructure projects and we will discuss some of the issues evaluators using QCA may run into when deploying the method in real-world evaluations.

\section{NOTE}

1. http://alrik-thiem.net/data/documents/glossary.pdf. 